\title{
PREVALENCE OF INFLAMMATORY BACK PAIN IN A LOW-INCOME POPULATION
}

Jobson Lopes de Oliveira ${ }^{1, \star}$, Rodolfo de Melo Nunes ${ }^{1}$, Guilherme Ferreira Maciel da Silva1', Igor Albuquerque Nogueira', Artur Queirós Azevedo ${ }^{1}$, Xenofon Baraliakos ${ }^{2}$, Francisco Airton Castro Rocha ${ }^{1}$

1.Universidade Federal do Ceará, Fortaleza (CE), Brazil. 2.Rheumazentrum Ruhrgebiet, Berlin, Germany.

*Corresponding author: jobson.oliveira88@gmail.com

\section{BACKGROUND}

Inflammatory back pain (IBP) is an important entry criterion for identifying patients with axial spondyloarthritis. Due to the very frequent prevalence of chronic noninflammatory back pain (CBP), IBP is difficult to differentiate and recognize in many clinical practices. Chronic noninflammatory back pain is a frequent diagnosis in populations with low socioeconomic status. The objective of this work was to investigate whether IBP ASAS definition help discriminate from CBP in a low-income population.

\section{MATERIALS AND METHODS}

A total of 202 consecutive individuals were directly interviewed in Fortaleza, Brazil, for the prevalence of IBP (ASAS definition), monthly family income (US\$), school education ( $>$ / $\leq 8$ school-years [SY]), and smoking habit (present/absent). People from all social levels were included.

\section{RESULTS}

Mean age was $38.9 \pm 12.9$ years, 100 (49.5\%) were male and 36 (17.8\%) were smokers; 135 (66.8\%) declared less than US\$ 730 family earnings per month and 71 (35.1\%) had less than 8 SY. Although 122 (60.3\%) declared lumbar pain, in comparison, 29 (14.3\%), 22 (10.9\%) and 59 (29.2\%) fulfilled ASAS, Berlin, and Calin's IBP criteria, respectively. There were 39 (58.02\%) vs. 83 (61.5\%) with vs. without CBP and 9 (13.4\%) vs. 20 (14.8\%) fulfilling vs. not fulfilling the ASAS IBP definition among those with more or less than US\$ 730 earnings $(p>0.05)$, respectively.

\section{CONCLUSION}

This is the first report on the prevalence of IBP in a very low-income population. Over one-third had less than 8 SY, revealing very low literacy. Smoking prevalence was also low if compared to $28 \%$ smoking prevalence that the World Health Organization estimates across Europe. These IBP prevalence data are similar to those reported in wealthier populations, living in higher latitude. Data suggest that ASAS IBP definition may be used to discriminate patients with IBP from those with CBP, regardless of income and literacy. 